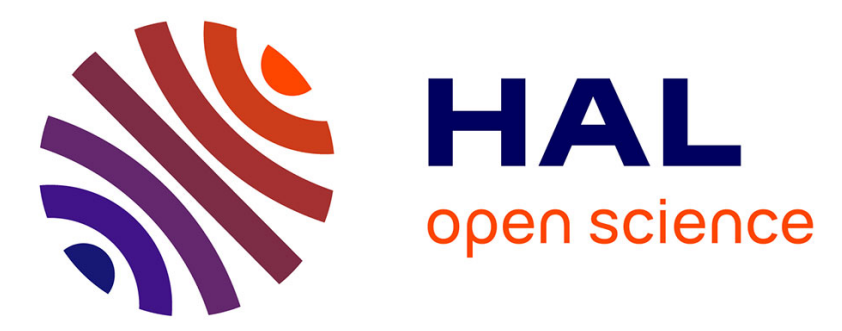

\title{
An investigation of the influence of moisture on fatigue damage mechanisms in a woven glass-fibre-reinforced PA66 composite using acoustic emission and infrared thermography
}

\author{
Amélie Malpot, Fabienne Touchard, Sébastien Bergamo
}

\section{To cite this version:}

Amélie Malpot, Fabienne Touchard, Sébastien Bergamo. An investigation of the influence of moisture on fatigue damage mechanisms in a woven glass-fibre-reinforced PA66 composite using acoustic emission and infrared thermography. Composites Part B: Engineering, 2017, 130, pp.11-20. 10.1016/j.compositesb.2017.07.017 . hal-02336910

\author{
HAL Id: hal-02336910 \\ https://hal.science/hal-02336910
}

Submitted on 19 Jul 2020

HAL is a multi-disciplinary open access archive for the deposit and dissemination of scientific research documents, whether they are published or not. The documents may come from teaching and research institutions in France or abroad, or from public or private research centers.
L'archive ouverte pluridisciplinaire HAL, est destinée au dépôt et à la diffusion de documents scientifiques de niveau recherche, publiés ou non, émanant des établissements d'enseignement et de recherche français ou étrangers, des laboratoires publics ou privés. 


\title{
An investigation of the influence of moisture on fatigue damage mechanisms in a woven glass-fibre-reinforced PA66 composite using acoustic emission and infrared thermography
}

\author{
Amélie Malpot $^{\mathrm{a}, \mathrm{b},{ }^{*}, \text { Fabienne Touchard }}{ }^{\mathrm{a}}$, Sébastien Bergamo ${ }^{\mathrm{b}}$ \\ ${ }^{a}$ Département Physique et Mécanique des Matériaux, Institut Pprime, CNRS-ENSMA-Université de Poitiers UPR 3346, ISAE-ENSMA, 1 avenue Clément Ader, \\ 86961 Futuroscope Chasseneuil, France \\ b UET DEA-TC-A3, Technocentre Renault, Les Labos, 1 Avenue du Golf, 78288 Guyancourt, France
}

\section{A R T I C L E I N F O}

\section{Article history:}

Received 15 March 2017

Received in revised form

6 June 2017

Accepted 13 July 2017

Available online 14 July 2017

\section{Keywords:}

Woven composite

Influence of moisture

Acoustic emission

Infrared thermography

\begin{abstract}
A B S T R A C T
A woven glass-fibre-reinforced composite with a polyamide 6,6 matrix is considered for the purpose of being integrated into an automotive part. Fatigue tests were conducted on both $\left[(0 / 90)_{3}\right]$ and $\left[( \pm 45)_{3}\right]$ stacking sequences. In order to analyze the influence of moisture content on the fatigue behaviour, samples were conditioned at RH0, RH50 and RH100. Although moisture content affects the fatigue life for high stress levels, this effect tends to disappear for low stress levels. This phenomenon was confirmed by additional fatigue tests in a climatic chamber. This paper aims to investigate damage mechanisms developing within the material during fatigue test in order to understand the origin of this phenomenon. Two in-situ non-destructive techniques were used in order to detail the fatigue damage scenario: namely, acoustic emission and infrared thermography. These techniques allow locating and differentiating the main damage mechanisms: matrix cracking, fibre/matrix debonding and fibre breakages. In addition, microscopic observations and synchrotron X-ray microtomography were realized on fatigue coupons to visualize fibre breakages. Results have highlighted an increase in the amount of fibre breakage when the applied fatigue stress decreases, which explains the observed phenomenon.
\end{abstract}

(c) 2017 Elsevier Ltd. All rights reserved.

\section{Introduction}

In order to reduce the $\mathrm{CO}_{2}$ emission level of vehicles, automotive manufacturers aim to maximize engine performance, improve vehicle's aerodynamics and reduce their mass. For the latter, the integration of composite components represents a high-potential solution. In this industrial context, composites with thermoplastic matrix are more attractive than thermosetting matrix due to their recyclability and their ease of application. However, some thermoplastic resins tend to be sensitive to moisture absorption, such as polyamide 6,6 (PA66) [1,2]. As a semi-crystalline polymer, PA66 is formed by a crystalline and an amorphous phase. The latter can be either in the glassy or the rubbery state, depending on the temperature. The limit between these two states is defined as the

\footnotetext{
* Corresponding author. Département Physique et Mécanique des Matériaux, Institut Pprime, CNRS-ENSMA-Université de Poitiers UPR 3346, ISAE-ENSMA, 1 avenue Clément Ader, 86961 Futuroscope Chasseneuil, France.

E-mail address: amelie.malpot@ensma.fr (A. Malpot).
}

glass transition temperature. In presence of water, polyamide molecules can interact with water molecules: hydrogen bonds between molecular chains are then disrupted. This reaction leads to an increase of the chains mobility: this phenomenon is known as the plasticizing effect of water [1,3]. As a consequence, the glass transition temperature tends to decrease when the moisture content increase. Mechanical properties are also affected by the presence of moisture since the strain at break increases while the stress at break and the Young modulus decrease [4,5].

When it comes to automotive applications, structural parts undergo cyclic loading in various temperature and moisture conditions. Several authors have studied the fatigue behaviour of composites with thermoplastic matrix, either with short fibres [6-8] or woven fabric $[9,10]$. Concerning the fatigue behaviour of woven composite, it has been shown in the literature that the earlier damage mechanism is fibre-matrix debonds leading to the cracking of transverse yarn [11]. Then, when the transverse crack has reached the edge of the yarn, either it propagates into a matrix-rich area or it is deflected into the adjacent longitudinal yarn, which is called meta-delamination [12]. Lastly, the final 
failure of the material is always the result of catastrophic failure of the longitudinal fibres. These damage mechanisms can be highlighted by using different non-destructive techniques as ultrasonic techniques [13], acoustic emission [12,14] and infrared thermography [15-17]. Acoustic emission is widely used for the monitoring of damage process in composite materials. The objective of this technique is to create clusters of acoustic events which possess similar acoustic signature (the signature being composed by the parameters which define the acoustic wave). Each cluster is then attributed to a specific damage mechanism. Clustering methods can be separated in two categories, namely parametric [18-21] or multi-parametric analysis [22-26]. Identification of these different damage mechanisms is often validated by microscopic observations or scanning electron microscopy (SEM) [12,21,27]. 3D observations of damages can also be performed by X-ray microtomography [28-30]. However, to be able to detect smallest damages like fibre breakages, the achieved voxel resolution has to be in the range of a few microns. This can be realized by using synchrotron radiation.

To our knowledge there is no publication about the influence of moisture on the fatigue life of a woven glass-fibre-reinforced thermoplastic composite. However, some authors have studied the effect of water on the fatigue life of thermoset composites [31-38]. Hu et al. [31] have studied the tension-tension fatigue behaviour of both UD glass/polydicyclopentadiene laminates and UD glass/epoxy laminates after ageing in salt water. They have showed that salt water ageing has a greater influence on lowcycle fatigue than on high-cycle fatigue. Patel and Case [35] have studied the influence of moisture on the fatigue life of a graphite/epoxy woven composite material. This study has shown that fatigue life of this type of composite is not affected by moisture.

This study is focused on a woven glass-fibre-reinforced composite with a polyamide 6,6 matrix. As, the PA66 behaviour is highly influenced by moisture content, three conditionings are studied: RHO, RH50 and RH100 which correspond respectively to the dry-asmoulded, the ambient and the water-saturated state. The influence of fabric orientation is also investigated through the study of three layups referred as $\left[(0 / 90)_{3}\right],\left[(90 / 0)_{3}\right]$ and $\left[( \pm 45)_{3}\right]$. First, S-N curves were established for all studied configurations at ambient temperature and hygrometry. To ensure that the initial conditioning of the samples remain the same during the entire cyclic solicitation, additional tests were done in a climatic chamber. By the association of infrared thermography and acoustic emission during fatigue tests, and post-mortem microscopic observations (optical microscopy and synchrotron X-ray microtomography), a damage scenario was then proposed.

\section{Materials and methods}

\subsection{Tested material}

The composite material studied is made of a 2/2 twill woven glass fabric impregnated with polyamide 6,6 resin (GFRPA66). The glass fibre fabric has a weight of $600 \mathrm{~g} / \mathrm{m}^{2}$ and a warp to weft ratio of $50 / 50$. The fibre mass fraction $\left(\mathrm{m}_{\mathrm{f}}\right)$ is equal to 0.63 and the void content is below $1 \%$. The resulting composite plates are characterized by a density of $1.78 \mathrm{~g} / \mathrm{cm}^{3}$. The material is provided as plates of $1.56 \mathrm{~mm}$ thick and dogbone coupons are cut using water jut cutting technique. It has been checked that this technique has no significant influence on the material moisture content.

The influence of fabric orientation on mechanical properties is studied using three different stacking sequences. The first one, referred as $\left[(0 / 90)_{3}\right]$, has the warp direction of each ply oriented at $0^{\circ}$ from the tensile axis ( $\mathrm{x}$ axis). The second one, referred as [(90/
$0)_{3}$ ], has the weft direction of each ply oriented at $0^{\circ}$ from the tensile axis ( $\mathrm{x}$ axis). Finally, the $\left[\left( \pm 45^{\circ}\right)_{3}\right]$ has the warp direction of each ply oriented alternately at $+45^{\circ}$ and $-45^{\circ}$ from the tensile axis.

Three conditionings were studied in order to evaluate the influence of moisture on the fatigue life of the composite: namely, RH0, RH50 and RH100. The first one corresponds to the dry-asmoulded state of the composite material. RH50 and RH100 coupons were conditioned in a climatic chamber until weight stabilization by the material supplier by following the standard ISO 1110 .

\subsection{Mechanical testing}

Monotonic tensile tests were performed using an INSTRON 4505 electromechanical machine with a cross-head speed of $1 \mathrm{~mm} / \mathrm{min}$, strain being measured by a $25 \mathrm{~mm}$ gauge length extensometer. Rectangular coupons were used with the dimensions of $200 \times 20 \times 1.56 \mathrm{~mm}$.

Fatigue tests were performed by using an INSTRON 8501 servohydraulic machine. For these tests, dogbone specimens were used in order to ensure the failure of the coupon in the gauge length. The dimensions of dogbone specimen are specified in Fig. 1.

The jaws of the test machine clamp $40 \mathrm{~mm}$ of each specimen extremity. In addition, 80 grit sand papers were used between the jaws and the sample to improve clamping. Constant amplitude loads were applied in a sinusoidal waveform at the frequency of $1 \mathrm{~Hz}$. The stress ratio $(\mathrm{R})$, i.e. ratio between minimum $\left(\sigma^{\mathrm{min}}\right)$ and maximum $\left(\sigma^{\max }\right)$ stresses, was equal to 0.1 for all tests.

\subsection{Non-destructive techniques}

\subsubsection{Acoustic emission (AE)}

Acoustic emission monitoring was performed by using the $\mathrm{AE}$ system from Mistras Group. Two sensors Micro-80 with a resonant frequency of $300 \mathrm{kHz}$ and an active surface diameter of $10 \mathrm{~mm}$ were used. They were placed at the gauge extremities of the specimen using silicon grease as the coupling agent. Sensors are separated with a distance of $100 \mathrm{~mm}$ between their centers. The amplitude threshold has been chosen equal to $35 \mathrm{~dB}$. Table 1 shows the settings of the AE system used.

Each test was preceded by a data acquisition calibration step. Using a pencil lead break procedure, the acoustic wave speed as well as the attenuation phenomenon was measured. For the latter, the lead breakage operation was repeated several times between the two sensors, at regular intervals (Hsu-Nielsen method). This procedure has shown that the attenuation phenomenon is negligible in the present work.

Post-processing was done using a multi-parametric identification, based on the k-means algorithm. The k-means algorithm aims to partition observations into $k$ clusters by minimizing the Euclidian distance between each observation and the nearest centre $\left(C^{k}=c_{1}, c_{2}, \ldots, c_{n}\right)$. This algorithm is unsupervised, which

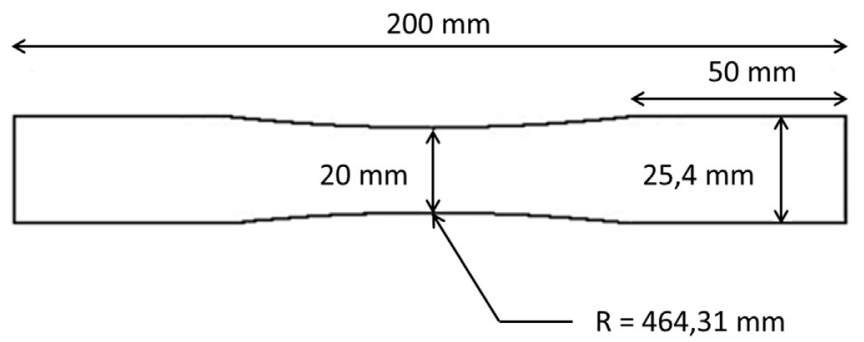

Fig. 1. Dimensions specification of dogbone specimen for fatigue testing. 
Table 1

Settings of the AE system.

\begin{tabular}{ll}
\hline Preamplifier gain & $40 \mathrm{~dB}$ \\
Threshold of detection & $35 \mathrm{~dB}$ \\
Type of sensors & Micro-80 \\
Couplant & Silicon grease \\
PDT (Peak Definition Time) & $30 \mu \mathrm{s}$ \\
HDT (Hit Definition Time) & $100 \mu \mathrm{s}$ \\
HLT (Hit Lockout Time) & $1000 \mu \mathrm{s}$ \\
Resonant Frequency & $300 \mathrm{kHz}$ \\
Bandwidth & $1 \mathrm{kHz}-3 \mathrm{MHz}$ \\
\hline
\end{tabular}

means that the number of clusters $k$ has to be known a priori. Observations are assimilated to a $n$-dimensional vector $\left(X=\mathrm{X}_{1}, \mathrm{X}_{2}\right.$, $\left.\ldots, \mathrm{X}_{\mathrm{n}}\right)$. The $\mathrm{k}$-means algorithm procedure can be detailed as follow:

1. Random initialization of the cluster centre for all $k$-classes $\left(\mathrm{C}^{\mathrm{k}}=\mathrm{c}_{1}, \mathrm{c}_{2}, \ldots, \mathrm{c}_{\mathrm{n}}\right)$.

2. Euclidian distance calculation between each observation and cluster centers.

3. Assignment of each observation to the cluster which minimize the Euclidian distance between the observation and the cluster centre.

4. Calculation of the new cluster centers for the new $k$-classes created.

5. Go to step 2 while there is change in the coordinates of the cluster centers.

In this study, observations are acoustic events and $n$ is chosen equal to five among all $\mathrm{AE}$ descriptors: amplitude, duration, rise time, energy and number of counts. Each cluster is then associated to one damage mechanism. Studies dealing with woven composite damage process have highlighted three major damage types: matrix cracking, interface damage and fibre breakage $[11,12,39,40]$. Thus, it was chosen to create three clusters. Attribution of each cluster to one particular damage mechanism was done by using previous results for clustering based on the amplitude only. Several authors [18, 19, 41-43] have shown that acoustic events with lower amplitudes are associated to matrix cracking whereas those with higher amplitudes are associated to fibre breakage. The intermediate range corresponds to interface damages (Table 2). Based on these results, each cluster was associated to one damage mechanism depending on its amplitude centre value.

\subsubsection{Infrared thermography}

An infrared camera from Cedip Infrared Systems with a detector resolution of $90 \mu \mathrm{m} /$ pixel was used. The energy radiated by the specimen can be converted into temperature levels assuming that the specimen emissivity is known. In this study, this parameter could not be determined experimentally. Thus, instead of the absolute temperature, the temperature variation at the surface of the specimen has been considered.

\subsection{Observations}

\subsubsection{Optical microscopy}

The edge of some specimens was observed by using an optical microscope ZEISS Axio Imager. Coupons were cut and cold mounted in an epoxy resin first. Then, samples were polished down to 1 $\mu \mathrm{m}$ before observations.

\subsubsection{X-ray tomography}

Two samples were observed on the line ID19 of the European Synchrotron Radiation Facility (ESRF) in Grenoble (France). These observations were done with a resolution of $3.06 \mu \mathrm{m} /$ pixel making it possible to visualize precisely the fibres within the sample. Image processing was done with the software Avizo.

\section{Results and discussion}

\subsection{Mechanical properties}

A preliminary study was completed in order to determine the mechanical tensile properties of the composite for both $\left[( \pm 45)_{3}\right]$ and $\left[(0 / 90)_{3}\right]$ layups and the three studied conditionings.

The ultimate tensile strength $\left(\sigma_{\mathrm{u}}\right)$, the strain at failure $\left(\varepsilon_{\mathrm{u}}\right)$, the Young modulus (E) and the Poisson ratio $(\nu)$ are shown in Table 3. It is worth noticing that the $\left[(0 / 90)_{3}\right]$ and $\left[(90 / 0)_{3}\right]$ layups have exhibited the same monotonic mechanical behaviour. More details can be found in a previous study [44].

Table 2

State of the art about the amplitude of acoustic events and the damage mechanisms related for different composite types.

\begin{tabular}{|c|c|c|c|c|c|}
\hline \multirow[t]{2}{*}{ Literature Review } & \multirow[t]{2}{*}{ Matrix } & \multirow[t]{2}{*}{ Fibres } & \multicolumn{3}{|l|}{ Amplitude Range } \\
\hline & & & Matrix Cracking & Interface Damage & Fibres Breakage \\
\hline [16] & Epoxy & Glass & {$[40-60 \mathrm{~dB}]$} & $65 \mathrm{~dB}$ & {$[90-95 \mathrm{~dB}]$} \\
\hline [15] & $\mathrm{PP}$ & Glass & {$[40-55 \mathrm{~dB}]$} & {$[60-85 \mathrm{~dB}]$} & {$[85-95 \mathrm{~dB}]$} \\
\hline [37] & Epoxy & Hemp & {$[35-53 \mathrm{~dB}]$} & [58-63 dB] & {$[66-100 \mathrm{~dB}]$} \\
\hline [38] & Epoxy & Flax & {$[42-60 \mathrm{~dB}]$} & {$[60-70 \mathrm{~dB}]$} & {$[70-100 \mathrm{~dB}]$} \\
\hline [39] & Polyester & Glass & {$[40-55 \mathrm{~dB}]$} & [55-70 dB] & {$[80-100 \mathrm{~dB}]$} \\
\hline
\end{tabular}

Table 3

Tensile properties for $\left[(0 / 90)_{3}\right]$ and $\left[( \pm 45)_{3}\right]$ composite layups at RH0, RH50 and RH100.

\begin{tabular}{|c|c|c|c|c|c|c|}
\hline & \multicolumn{3}{|l|}{$\left[( \pm 45)_{3}\right]$} & \multicolumn{3}{|c|}{$\left[(0 / 90)_{3}\right]$ and $\left[(90 / 0)_{3}\right]$} \\
\hline & RHO & RH50 & RH100 & RHO & RH50 & RH100 \\
\hline$\sigma_{\mathrm{u}}[\mathrm{MPa}]$ & $143.0 \pm 8.1$ & $124.4 \pm 1.1$ & $102.3 \pm 1.0$ & $377.7 \pm 11.0$ & $343.5 \pm 1.0$ & $290 \pm 3.0$ \\
\hline $\begin{array}{l}\varepsilon_{\mathrm{u}} \\
{[\%]}\end{array}$ & $13.30 \pm 0.70$ & $18.45 \pm 1.39$ & $24.10 \pm 2.30$ & $2.15 \pm 0.06$ & $2.05 \pm 0.04$ & $1.84 \pm 0.10$ \\
\hline $\mathrm{E}$ [GPa] & $6.8 \pm 0.8$ & $2.6 \pm 0.1$ & $1.3 \pm 0.1$ & $19.6 \pm 0.4$ & $17.5 \pm 0.5$ & $16.2 \pm 0.8$ \\
\hline$\nu$ & $0.625 \pm 0.045$ & $0.885 \pm 0.002$ & $0.907 \pm 0.032$ & $0.072 \pm 0.021$ & $0.070 \pm 0.009$ & $0.065 \pm 0.009$ \\
\hline
\end{tabular}



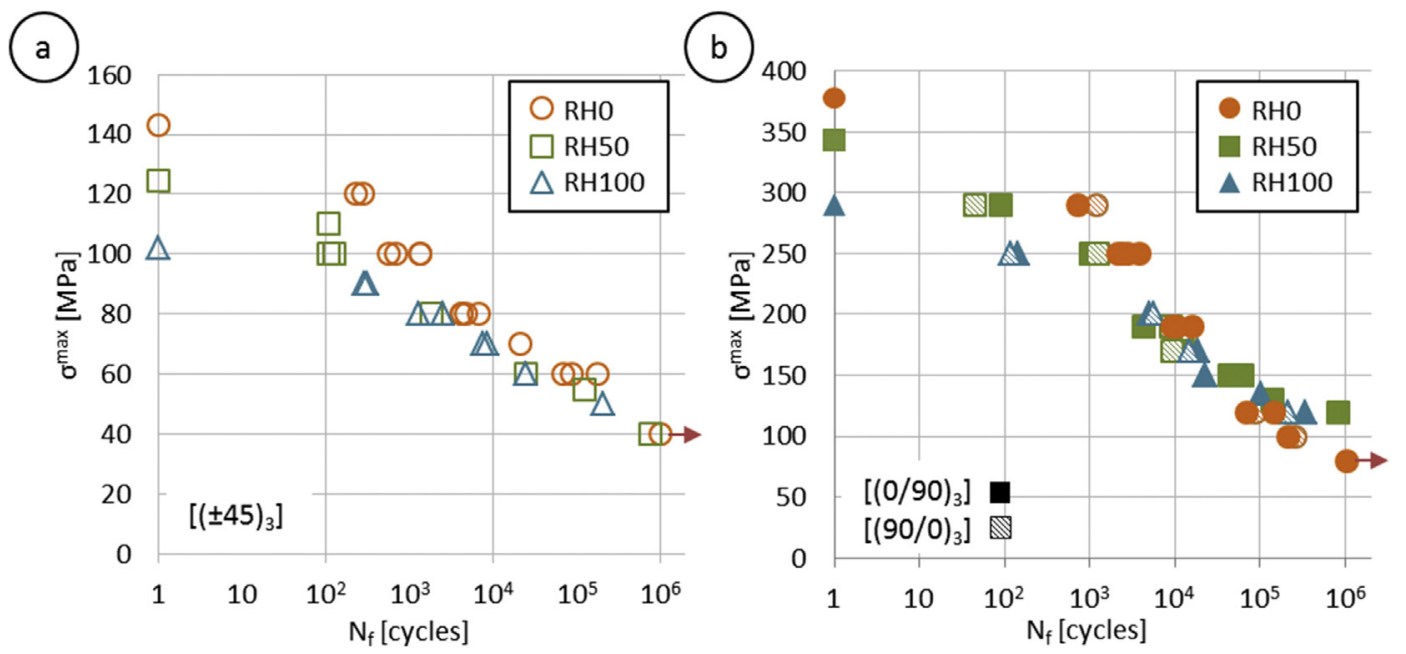

Fig. 2. S-N curves of the GFRPA66 composite for three moisture conditions (RH0, RH50 and RH100) for (a) $\left[( \pm 45)_{3}\right]$ and (b) $\left[(0 / 90)_{3}\right]$ and $\left[(90 / 0)_{3}\right]$ layups.

\subsection{Fatigue life}

Fatigue tests were performed on $\left[(0 / 90)_{3}\right],\left[(90 / 0)_{3}\right]$ and $\left[( \pm 45)_{3}\right]$ layups until failure of coupons. A fatigue life model has been developed in a previous study $[45,46]$.

\subsubsection{Influence of conditioning on fatigue life}

Fatigue tests were first performed at ambient temperature and hygrometry. Fig. 2 shows S-N curves for all configurations tested. For the $\left[( \pm 45)_{3}\right]$ layup, 29 samples were tested in fatigue. For the $\left[(0 / 90)_{3}\right]$ and $\left[(90 / 0)_{3}\right]$ layups, 34 samples were tested. Samples that did not fail after $10^{6}$ cycles were stopped and arrowheads were added in Fig. 2. The dispersion of fatigue lives is about half a decade, which is quite low for a composite material. This little scattering may be a direct consequence of the low porosity of the material $(<1 \%)$. As expected, both $\left[(0 / 90)_{3}\right]$ and $\left[(90 / 0)_{3}\right]$ layups show the same fatigue behaviour (Fig. 2b).

Below $10^{4}$ cycles, the increase of the relative humidity content within the sample implies a reduction of the fatigue life. At the opposite, above $10^{4}$ cycles, the conditioning does not seem to influence the fatigue life anymore. This would indicate that for the lower fatigue stress, the fatigue life is independent of the moisture content in the coupon.

Since fatigue tests were performed at ambient temperature and hygrometry, it is possible that the moisture content would change during fatigue tests of several hours. For instance, samples initially conditioned at RH100 might dry during fatigue tests whereas samples initially conditioned at RHO might take up moisture from the air. As a consequence, both RH100 and RH50 S-N curves could get closer to the RH50 S-N curve. Thus, to check this theory, fatigue tests were reproduced in a climatic chamber with temperature and hygrometry regulation.

\subsubsection{Influence of hygrometry conditions}

In order to maintain the samples conditioning at its initial state, some RH0 and RH100 samples were tested in a climatic chamber, respectively at $15 \%$ and $95 \%$ of relative humidity and $20^{\circ} \mathrm{C}$. Results are presented in Fig. 3 as well as the fatigue lives determined at ambient hygrometry for comparison. Fatigue lives of samples tested in the climatic chamber are slightly higher that the equivalent fatigue life determined at ambient hygrometry. However, this increase is not significant and is in the dispersion range.
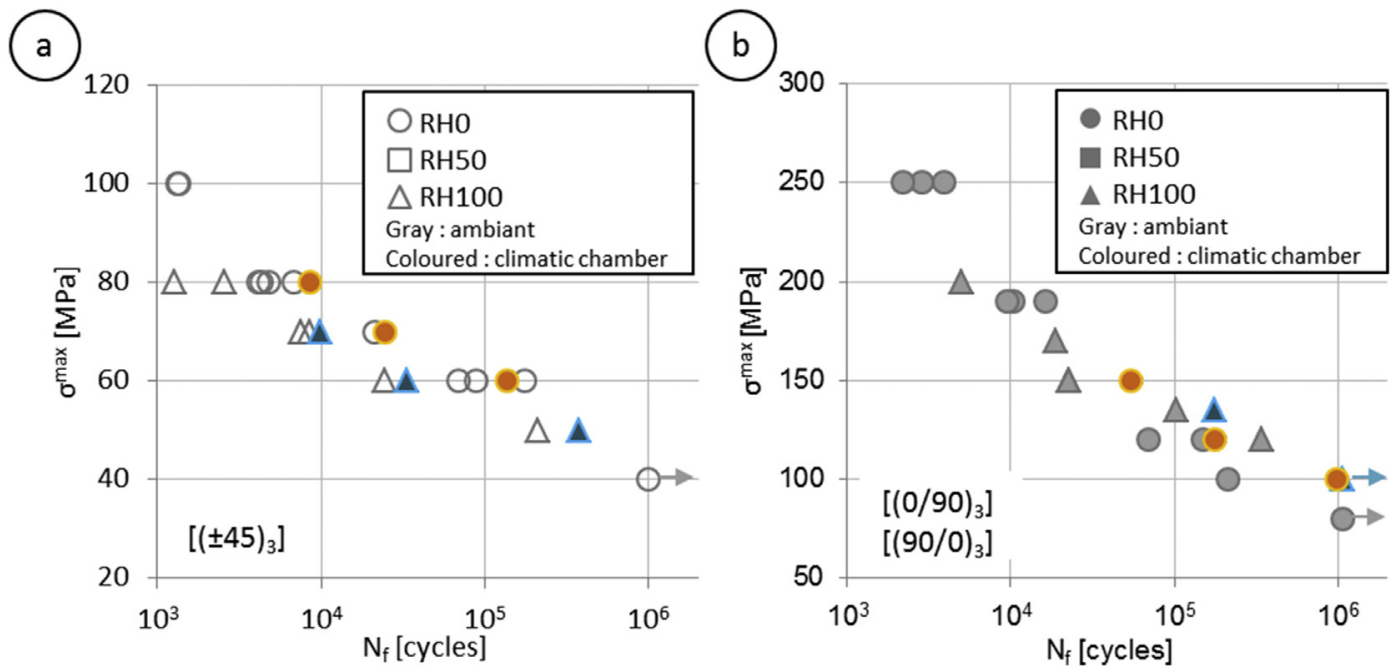

Fig. 3. Influence of the testing moisture conditions on the fatigue life of GFRPA66 composite at RH0 and RH100 for (a) $\left[( \pm 45)_{3}\right]$ and (b) $\left[(0 / 90)_{3}\right]$ layups. 
(a)

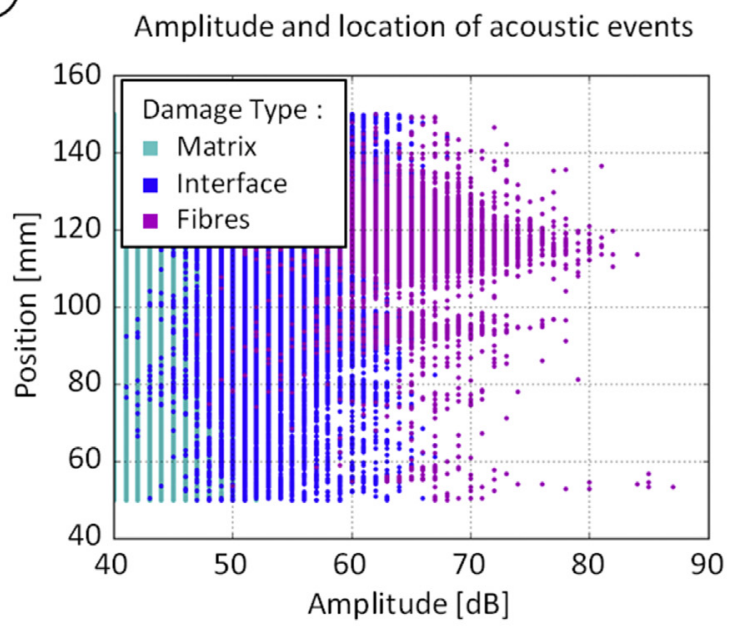

Temperature elevation $\left({ }^{\circ} \mathrm{C}\right)$
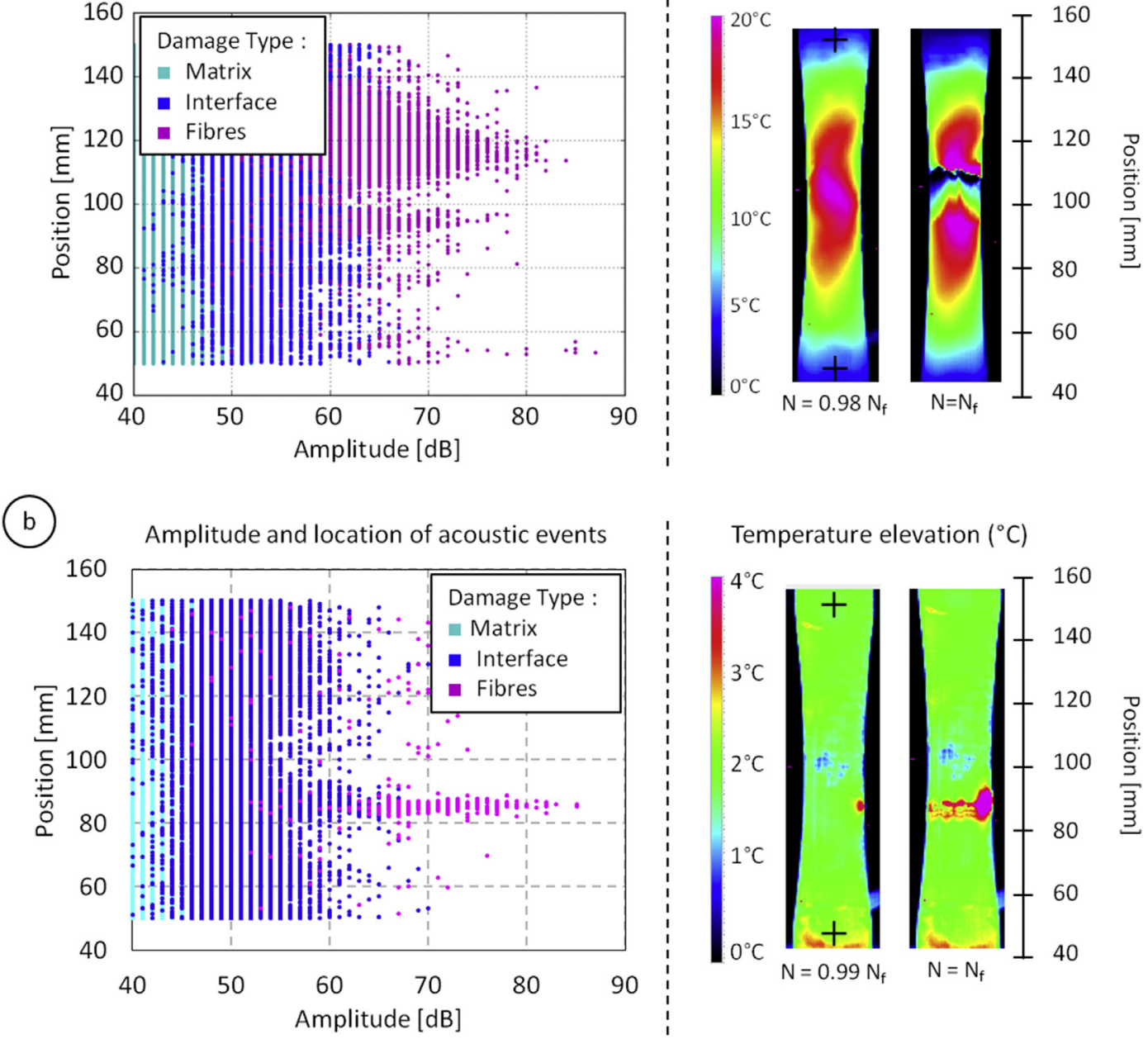

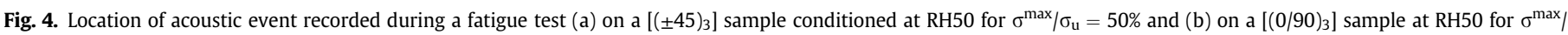
$\sigma_{\mathrm{u}}=55 \%$. Comparison with temperature elevation cartographies (IR thermography).

Finally, these tests show that the S-N curves determined at ambient temperature and hygrometry are relevant in the context of this study (Fig. 2). Thus, the reunification of the RHO, RH50 and RH100 S-N curves beyond $10^{4}$ cycles is not due to a testing artefact but to a material characteristic. A damage analysis was then performed in order to understand this phenomenon.

\subsection{Damage analysis}

In situ damage analysis was performed by combining acoustic emission and infrared thermography during fatigue tests.

\subsubsection{Damage location}

Acoustic events are recorded during fatigue tests and then attributed to a specific damage mechanism among matrix cracking, interface damage and fibre breakage. They are also located in the gauge length of the coupon, along the $\mathrm{x}$ axis. By the same time, temperature elevation cartography is determined using infrared (IR) thermography.

Fig. 4a shows results for a $\left[( \pm 45)_{3}\right]$ sample (RH50) for a fatigue loading level of $\sigma^{\max }=50 \% \sigma_{\mathrm{u}}$. Acoustic events are relatively well distributed along the gauge length. However, an accumulation of acoustic events related to fibre breakage is observed at $118 \mathrm{~mm}$.
This abscissa is consistent with the location of the failure, as shown by IR thermography image. IR cartography shows that the heating of the sample is very important (above $20^{\circ} \mathrm{C}$ ) and affect the main part of the gauge length. This observation is in accordance with the distribution of acoustic events and tends to demonstrate that, for this layup, damage is distributed all along the gauge length until failure.

Fig. 4 b shows results for a $\left[(0 / 90)_{3}\right]$ sample (RH50) for a fatigue loading level of $\sigma^{\max }=55 \% \sigma_{\mathrm{u}}$. Whereas matrix-related and interface-related events are distributed all along the gauge length, acoustic events related to fibre breakage are mainly located around the future failure location. Before failure, IR cartography shows a temperature elevation $\left(4^{\circ} \mathrm{C}\right)$ at the same abscissa. These results show that the temperature elevation in the sample is strongly linked to the fibre breakage mechanism since the development of the latter is highly localized for this stacking sequence. For both layups, this in-situ damage analysis shows that the ultimate failure is driven by fibre breakages.

\subsubsection{Damage evolution}

Infrared thermography allows the study of the surface heating for both $\left[(0 / 90)_{3}\right]$ and $\left[( \pm 45)_{3}\right]$ layups. The latter is characterized by an important temperature rise from the very beginning of the fatigue 
tests, in the whole gauge length (Fig. 4). The final surface heating, at the time of failure reaches $20^{\circ} \mathrm{C}$. This temperature rise is mainly due to the fibre orientation for this stacking sequence. The presence of fibres oriented at $\pm 45^{\circ}$ from the loading axis leads to the reorientation of fibres at each cycle. This cyclic change in the fibres angle is probably at the origin of internal friction resulting in temperature rise in the whole gauge length. At the opposite, $\left[(0 / 90)_{3}\right]$ coupons do not experienced surface heating in the gauge length during fatigue tests. Only a small heating point appears in the last cycles of the fatigue life, indicating a high damage level in this area.

For both $\left[(0 / 90)_{3}\right]$ and $\left[( \pm 45)_{3}\right]$ layups and all conditionings, acoustic emission recordings allow an analysis of the evolution of damage mechanisms: matrix cracking, fibre/matrix debondings (interface) and fibre breakages.

Fig. 5a shows for instance the evolution of the cumulative number of acoustic events for each type of damage during the fatigue lives of $\left[(0 / 90)_{3}\right]$ samples tested at $\sigma^{\max } / \sigma_{\mathrm{u}}=50 \%$ and conditioned at RH0, RH50 and RH100. These results indicate that the evolution of the cumulative number of acoustic events is dependent of the conditioning. Results obtained for $\left[( \pm 45)_{3}\right]$ layup (not presented in this study) and for other fatigue loadings have shown that the cumulative number of acoustic events is also highly dependent of both the stacking sequence and the value of the ratio $\sigma^{\max } / \sigma_{\mathrm{u}}$.

Fig. 5b shows the final distribution (at the time of failure) of acoustic events for the three damage mechanisms and for different
Table 4

Influence of the stacking layup and the conditioning on the distribution of acoustic events recorded at the end of fatigue tests for $\sigma^{\max } / \sigma_{\mathrm{u}}=50 \%$ for each damage mechanism.

\begin{tabular}{|c|c|c|c|c|c|c|c|}
\hline & \multirow{2}{*}{$\sigma^{\max } / \sigma_{u}=50 \%$} & \multicolumn{3}{|c|}{$\left[( \pm 45)_{3}\right]$} & \multicolumn{3}{|c|}{$\left[(0 / 90)_{3}\right]$} \\
\hline & & RHO & RH50 & RH100 & RHO & RH50 & RH100 \\
\hline \multirow[t]{3}{*}{ Damage Type } & Matrix [\%] & 56.0 & 52.0 & 35.5 & 73.9 & 69.4 & 65.2 \\
\hline & Interface [\%] & 34.2 & 41.8 & 50.5 & 25.6 & 29.1 & 29.9 \\
\hline & Fibres [\%] & 9.7 & 6.2 & 13.9 & 0.5 & 1.4 & 5.0 \\
\hline
\end{tabular}

fatigue loading levels. From these results, it appears that the proportion of matrix-related and interface-related events is highly dependent of the applied fatigue stress and the conditioning of samples. However, one common trend appears for all conditionings: the reduction of the fatigue stress applied induces an increase of the proportion of fibre-related events. In order to study the influence of stacking sequence and conditioning on the distribution of acoustic levels, Table 4 proposes a comparison for an equivalent fatigue level of $\sigma^{\mathrm{max}} / \sigma_{\mathrm{u}}=50 \%$. Irrespective of the stacking sequence, the increase of the moisture content implies a reduction in the acoustic activity of the matrix and an increase in the acoustic activity of the interfaces. Moreover, the number of fibre breakages tends to grow with the humidity content. Finally, these results indicate also that the damage of interfaces and fibres is more important for the $\left[( \pm 45)_{3}\right]$ layup than the $\left[(0 / 90)_{3}\right]$.
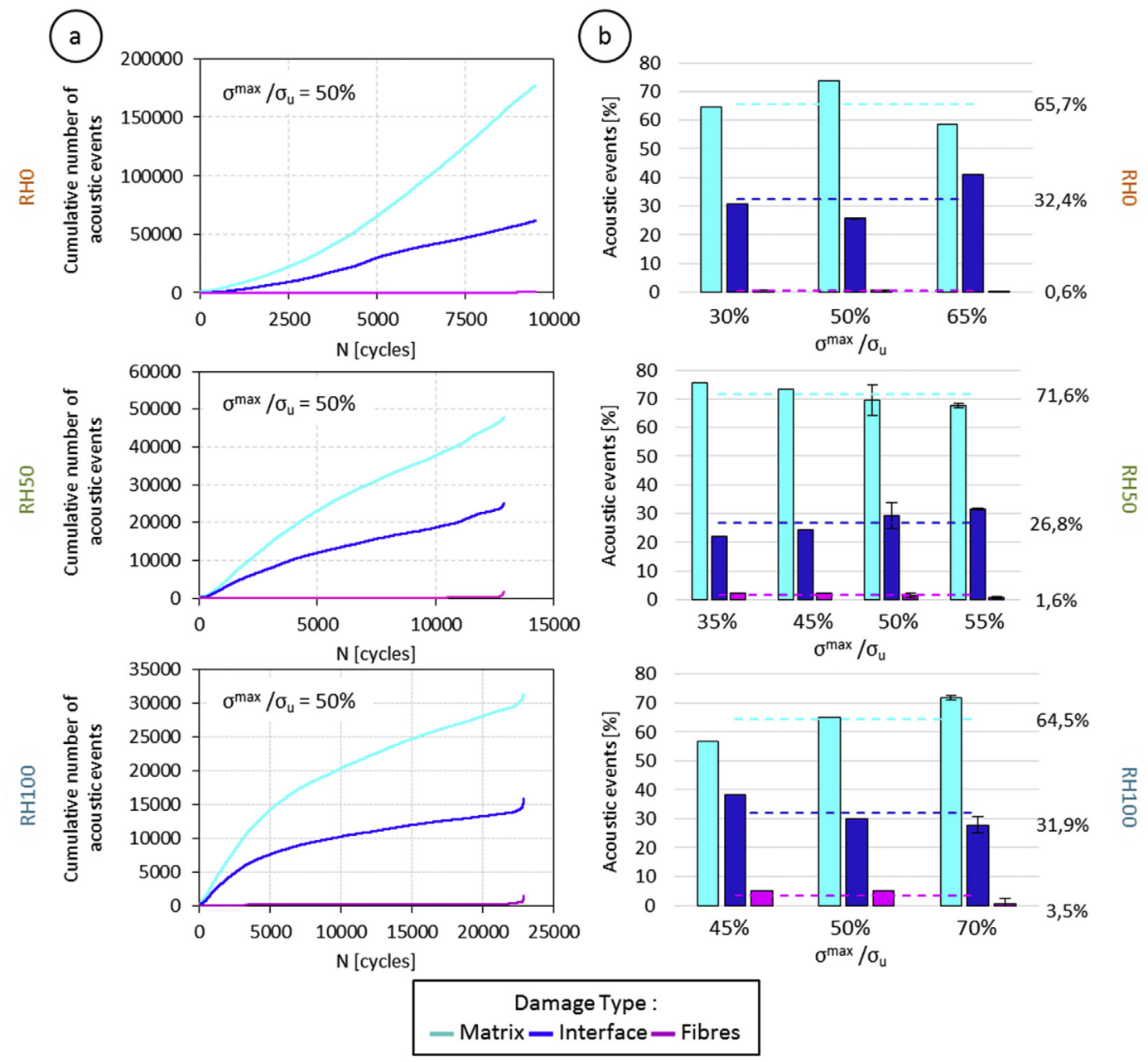

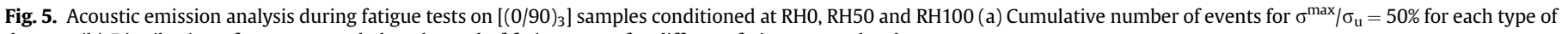
damage (b) Distribution of events recorded at the end of fatigue tests for different fatigue stress levels. 


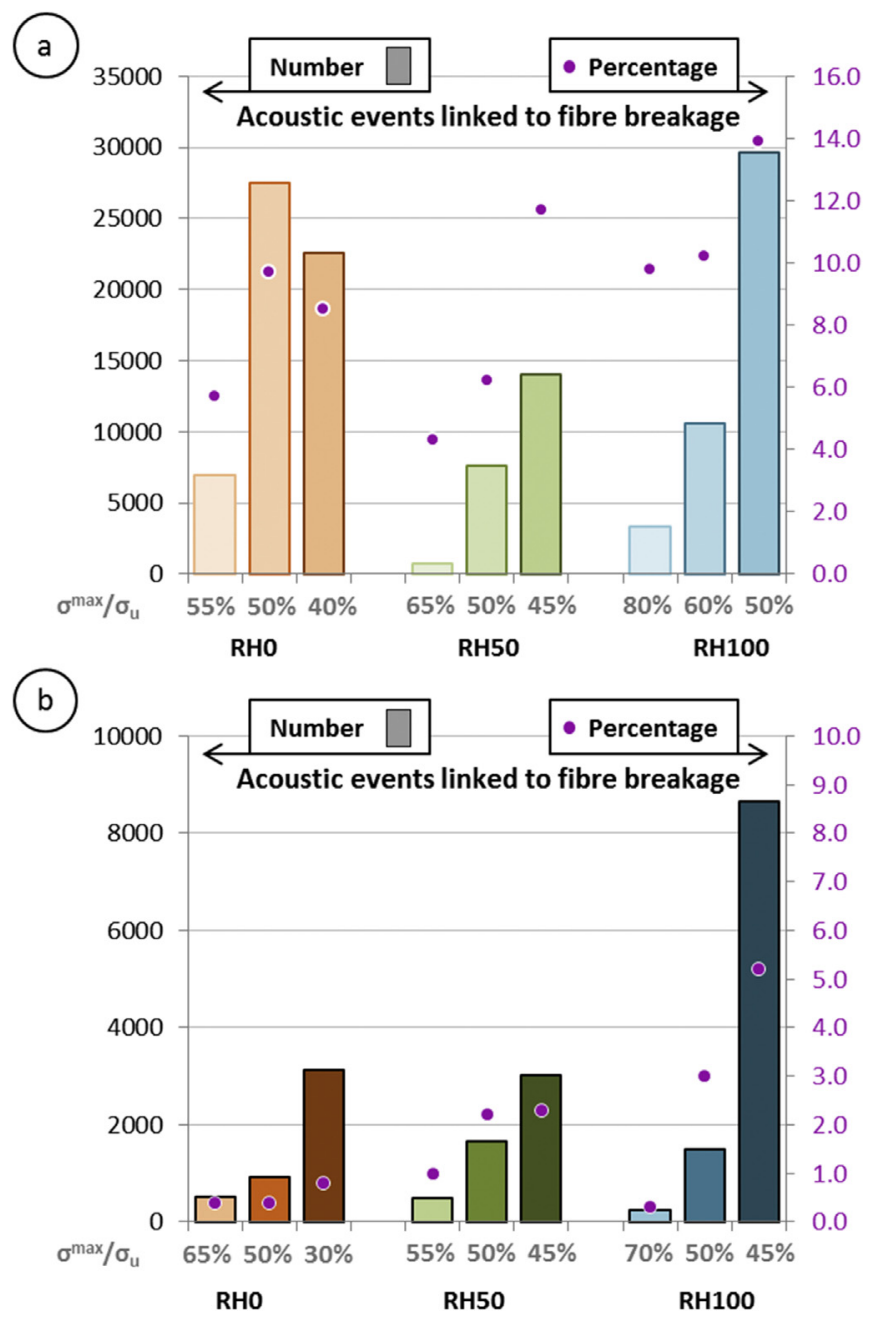

Fig. 6. Absolute number and percentage of acoustic events related to fibre damage recorded at the end of fatigue tests $(R=0.1$ and $f=1 \mathrm{~Hz})$ for different fatigue stress levels and the three studied conditionings: (a) $\left[( \pm 45)_{3}\right]$ layup and (b) $\left[(0 / 90)_{3}\right]$ layup.

\subsection{Influence of fatigue stress on fibre breakage}

\subsubsection{Number of acoustic events related to fibre breakage}

In this part, only acoustic events related to fibre breakage are considered. In order to study the influence of the fatigue stress level, three $\sigma^{\mathrm{max}} / \sigma_{\mathrm{u}}$ ratios were analysed for each configuration studied. Absolute number of acoustic events related to fibre damage is reported in Fig. 6 for the three conditionings and the two layups studied. The corresponding percentage, namely the number of acoustic events related to fibre damage divided by the total number of acoustic events recorded, is also shown in this figure.

For the $\left[( \pm 45)_{3}\right]$ layup, apart from samples conditioned at RH0, the lower the fatigue stress applied, the higher the number of acoustic events related to fibre damage. This observation is also true if the percentage of acoustic events related to fibre damage is considered (Fig. 6a). For the $\left[(0 / 90)_{3}\right]$ layup, the reduction of the fatigue stress level implies an increase of the number and the percentage of acoustic events related to fibre damage (Fig. 6b). Moreover, it seems that this phenomenon is exacerbated by the increase of the moisture content of the sample. A comparison between the two layups shows that the fibre damage mechanism is always more important for the $\left[( \pm 45)_{3}\right]$ layup.

\subsubsection{Linear density of fibre breakage}

Interrupted fatigue tests were done on both $\left[( \pm 45)_{3}\right]$ and $[(0 /$ $90)_{3}$ ] samples conditioned at RH50. As previously, three loading levels were applied in order to study the influence of the fatigue stress on the fibre damage mechanism. Tests were interrupted at $\mathrm{N}_{\mathrm{f}} / 2$ and then, coupons were cut, cold-mounted and polished in order to be observed (Fig. 7 ). $\left[( \pm 45)_{3}\right]$ samples were cut in the fibres direction in order to visualize fibres either in the longitudinal or the transverse view.

These observations are used in order to count the number of longitudinal broken fibres at $\mathrm{N}_{\mathrm{f}} / 2$. In order to determine a linear density of fibre breakages, the number of broken fibres is divided by the length of observed sample. Results are shown in Fig. 8 for both $\left[( \pm 45)_{3}\right]$ and $\left[(0 / 90)_{3}\right]$ layups at three fatigue loading levels.

For the $\left[( \pm 45)_{3}\right]$ layup, the linear density of fibre breakages is doubled when the loading level decreases from $60 \%$ to $50 \%$. One can notice a not significant decrease when the applied fatigue stress is reduced by $5 \%$ (Fig. $8 \mathrm{a}$ ). For the $\left[(0 / 90)_{3}\right]$ layup, the linear density of fibre breakages increases gradually when the fatigue loading level decreases. However, its value is multiplied by three when the fatigue loading level drops from $70 \%$ to $45 \%$ of the material strength (Fig. 8b). The comparison of the two layups shows that the linear density of broken fibres is higher for the $\left[( \pm 45)_{3}\right]$ stacking sequence. These results are consistent with information given by acoustic emission and presented in section 3.4.1.

\subsubsection{Volume ratio of fibre breakage}

Two $\left[(0 / 90)_{3}\right]$ coupons conditioned at RH50 were tested respectively at $70 \%$ and $40 \%$ of the ultimate strength at $1 \mathrm{~Hz}$ and $\mathrm{R}=0.1$ in order to be analysed by synchrotron XR tomography. Fatigue tests were instrumented with acoustic emission and infrared thermography and were interrupted at $\mathrm{N}_{\mathrm{f}} / 2$. For both
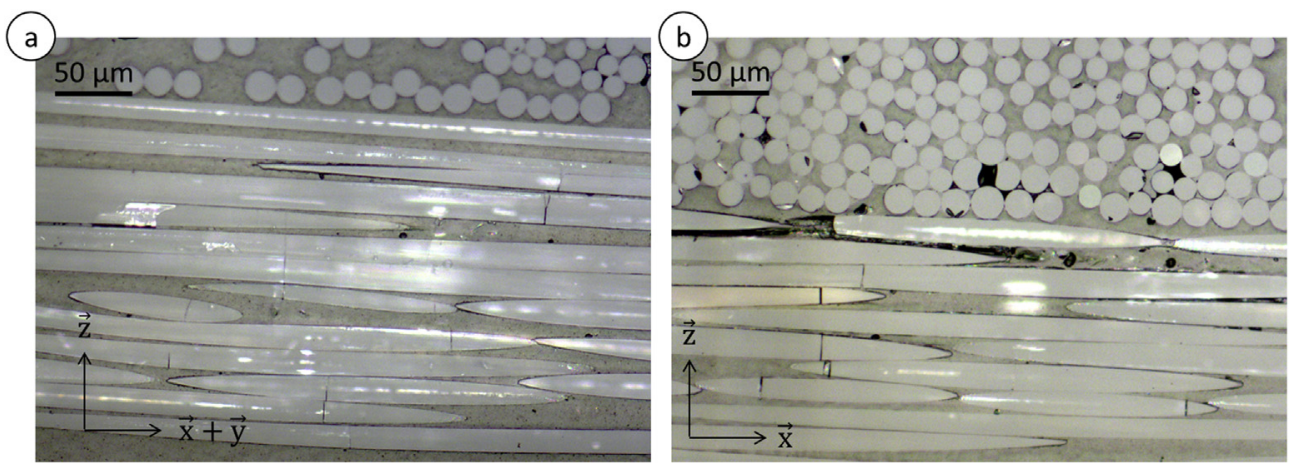

Fig. 7. Microscopic observations of $(\mathrm{a})\left[( \pm 45)_{3}\right]$ and $(\mathrm{b})\left[(0 / 90)_{3}\right]$ samples conditioned at RH50. Interrupted fatigue tests at $\mathrm{N}_{\mathrm{f}} / 2$. 

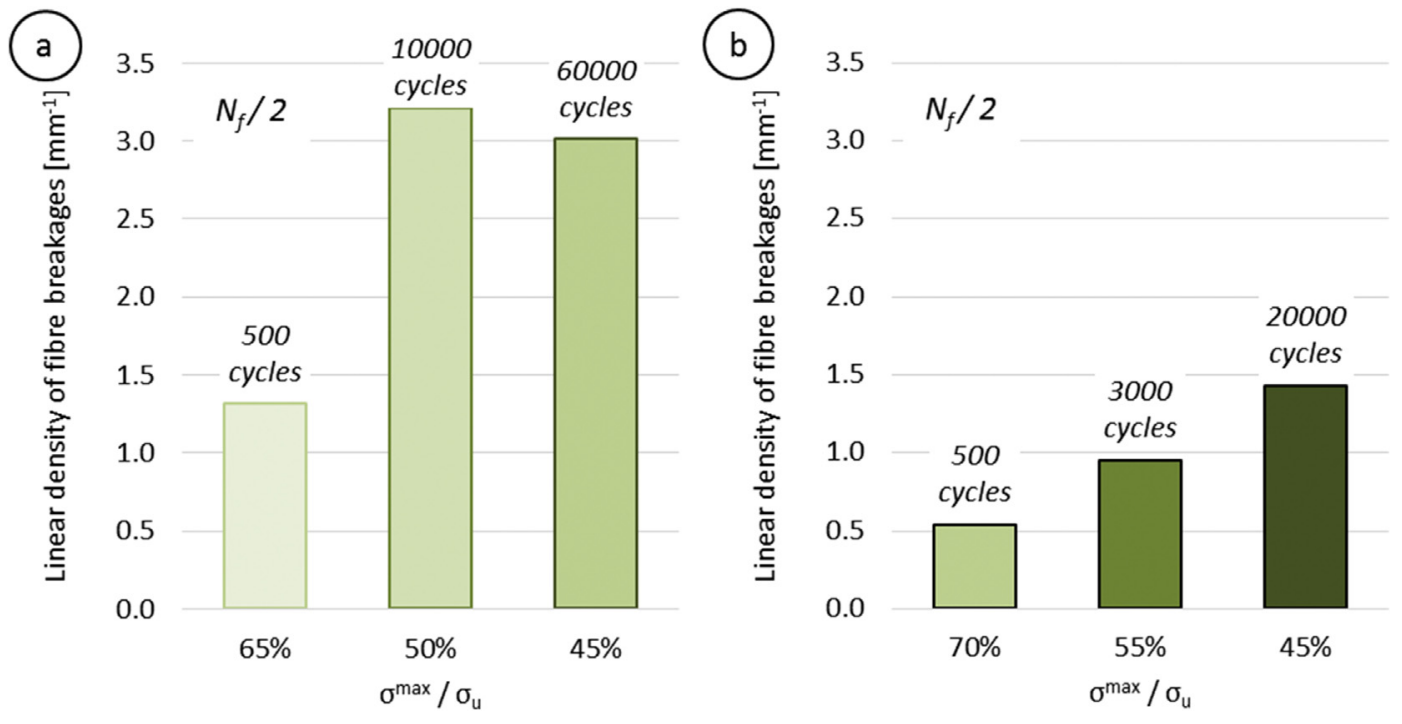

Fig. 8. Linear density of fibre breakages for $(a)\left[( \pm 45)_{3}\right]$ and (b) $\left[(0 / 90)_{3}\right]$ samples tested at $R=0.1$ and $f=1$ Hz. Interrupted tests at $N_{f} / 2$ for three fatigue loading levels.

samples, the choice of the tomography scan location was driven by the presence of a slight surface heating recorded by IR thermography associated to few fibre-related acoustic events. High resolution XR tomography scans were performed on samples of the size $12 \times 20 \times 1.56 \mathrm{~mm}$, which represents a total volume of $376.8 \mathrm{~mm}^{3}$.

In order to isolate longitudinal fibre breakages on tomography scans, post-processing is done by using the software Avizo as detailed on Fig. 9. From a sub volume, a Gaussian filter is applied in order to reduce the image noise (Fig. 9a). Then, the "image gradient" filter is applied: this filter allows highlighting fibre breakages as well as smoothing the longitudinal yarn in which they are located (Fig. 9b). Next, fibre breakages can be isolated by applying the appropriate threshold (Fig. 9c). However, this operation also leads to the selection of some transverse fibres, thus, it is necessary to perform a sieve analysis in order to exclude these fibres. This final step generates two groups, represented in Fig. 9d in yellow and red, corresponding respectively to the transverse fibres and the fibre breakages. It is necessary to precise that the term "fibre breakages" corresponds in fact to the void arising from the rupture of the fibre.

The volume fractions corresponding to fibre breakages determined by using this post-processing are shown in Table 5. As the number of acoustic events or the linear density, the volume fraction related to fibre damage increases when the fatigue stress applied decreases.
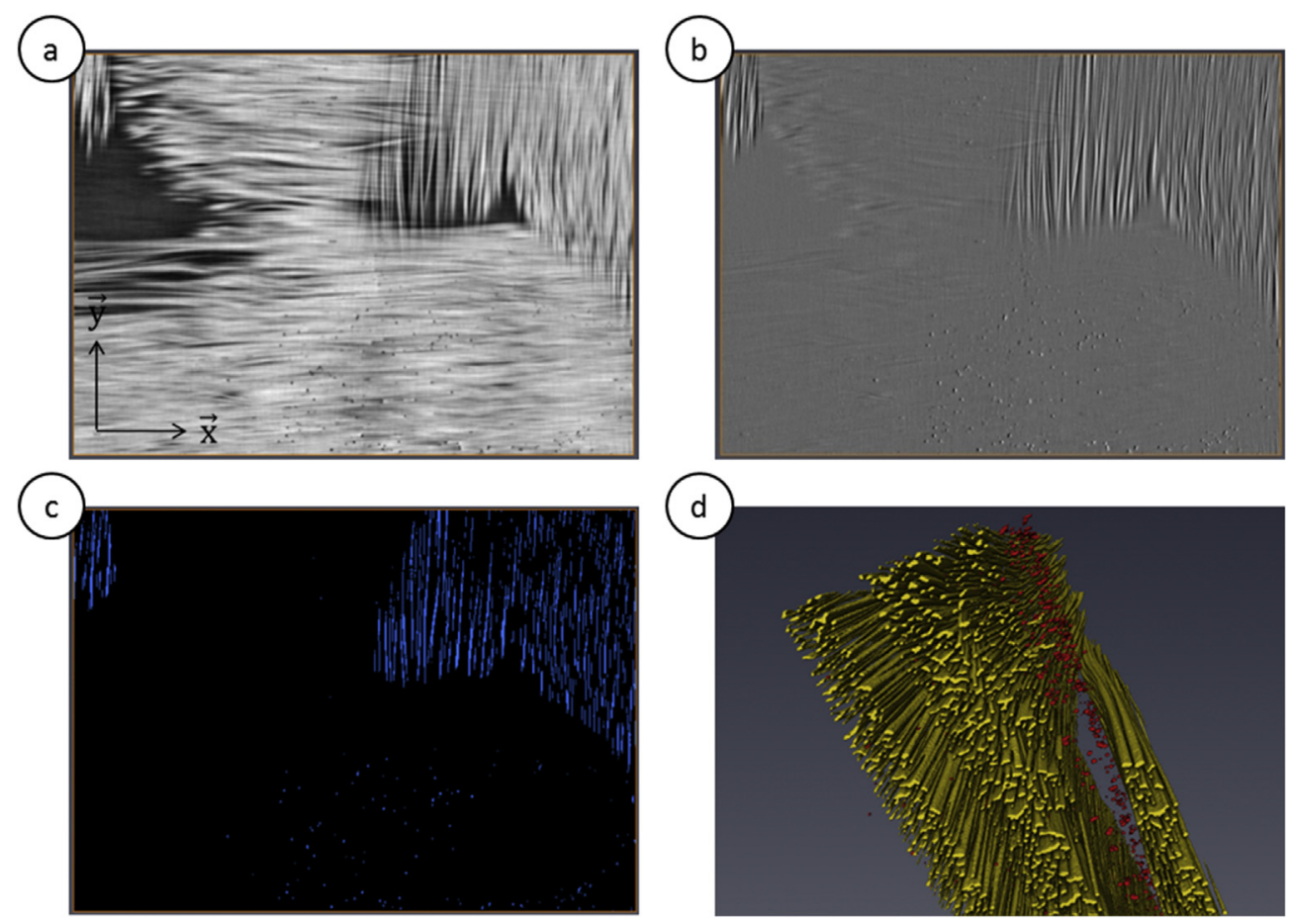

Fig. 9. Illustration of the different steps of synchrotron image post-processing using Avizo. 
Table 5

Volume fraction corresponding to fibre breakage for two GFRPA66 [ $\left.0 / 90)_{3}\right]$ samples conditioned at $\mathrm{RH} 50$ and tested in fatigue at $70 \%$ and $40 \%$ of the ultimate strength until $\mathrm{N}_{\mathrm{f}} / 2$.

\begin{tabular}{lll}
\hline & $\sigma^{\max }=70 \% \sigma_{\mathrm{u}}$ & $\sigma^{\max }=40 \% \sigma_{\mathrm{u}}$ \\
\hline $\mathrm{V}_{\text {fibre breakages }} / \mathrm{V}_{\text {toatal }}$ & $15.7 \times 10^{-5}$ & $24.4 \times 10^{-5}$ \\
\hline
\end{tabular}

Table 6

Indicators of the amount of fibre breakages in the damage process for $\left[( \pm 45)_{3}\right]$ and $\left[(0 / 90)_{3}\right]$ samples conditioned at RH50 for three fatigue stress levels.

\begin{tabular}{llllll}
\hline & $\sigma^{\mathrm{max}} / \sigma^{\mathrm{u}}[\%]$ & $\log \left(\mathrm{N}_{\mathrm{f}}\right)$ & $\mathrm{l}_{\text {fibres }}\left[\mathrm{mm}^{-1}\right]$ & $\mathrm{v}_{\text {fibres }}$ & $\mathrm{n}_{\text {EA,fibres }}$ \\
\hline$\left[(0 / 90)_{3}\right]$ & 70 & 3.0 & 0.54 & $15.7 \times 10^{-5}$ & 300 \\
& 55 & 3.6 & 0.95 & - & 480 \\
& $40-45$ & 4.7 & 1.43 & $24.4 \times 10^{-5}$ & 3012 \\
\hline$\left[( \pm 45)_{3}\right]$ & 65 & 3.2 & 1.32 & - & 735 \\
& 50 & 4.4 & 3.21 & - & 7609 \\
& 45 & 5.1 & 3.01 & - & 13981 \\
\hline
\end{tabular}

\subsubsection{Discussion}

Several indicators, shown in Table 6, have been studied in order to understand the role of fibres in the damage process of a GFRPA66 composite:

- The number of acoustic events related to fibre breakages recorded at the time of failure ( $\mathrm{n}_{\mathrm{EA}, \mathrm{fibres}}$ );

- The linear density of fibre breakages counted from microscopic observations at half the lifetime $\left(\mathrm{l}_{\text {fibres }}\right)$;

- The volume fraction corresponding to fibre breakage determined by using synchrotron XR tomography at half the lifetime $\left(v_{\text {fibres }}\right)$;

All these parameters indicate that there is an increase of the number of broken fibres during the fatigue test when the fatigue stress applied decreases. According to Table 6, the stress threshold is about $50 \%$ of the stress at break. This value corresponds to a fatigue life close to $10^{4}$ cycles.

Fig. 10 represents the S-N curve of the $\left[(0 / 90)_{3}\right]$ layup conditioned at RH50 superimposed with S-N curves found in the literature for neat PA66, neat PA6 and unimpregnated bundles ( 30 glass fibres) [47]. Fatigue tests were performed at the same load ratio $(\mathrm{R}=0.1)$. Maximum fatigue stress applied has been normalized by the ultimate strength of the considered material. Fig. 10 shows that the composite S-N curve is close to the neat resin S-N curve for low

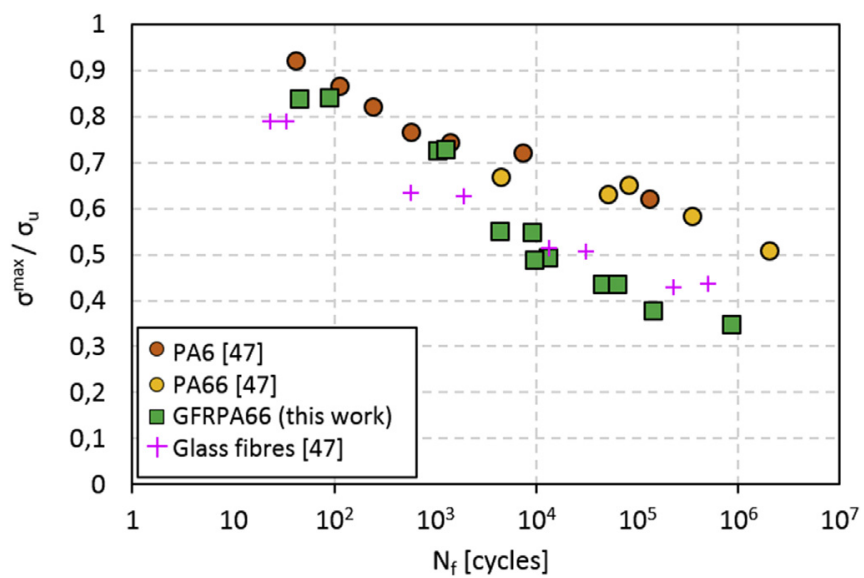

Fig. 10. Comparison of S-N curves for the GFRPA66 $\left[(0 / 90)_{3}\right]$ at RH50 with data on neat resin and unimpregnated glass fibres from the literature. fatigue life, and close to the glass fibres S-N curve for high fatigue life. It confirms the results obtained in Table 6: the longitudinal fibres experienced fatigue breakage in the case of low fatigue stress applied. In addition, section 3.3.1 has previously shown that fibres breakages are at the origin of the failure of samples (Fig. 4).

All these data support the assumption that for low fatigue stress, and thus high fatigue life, the coupon failure is driven by the fatigue behaviour of the longitudinal fibers. Since fibres are insensitive to moisture, this can explain that the conditioning of samples has no influence on the fatigue life of the composite for this range of applied stress (Fig. 2).

\section{Conclusion}

This study deals with the fatigue damage process of a woven glass-fibre-reinforced composite with polyamide 6,6 matrix. Two layups were deeply studied, namely $\left[(0 / 90)_{3}\right]$ and $\left[( \pm 45)_{3}\right]$ as well as three conditionings referred as RHO, RH50 and RH100. First, fatigue tests were performed on all configurations at ambient hygrometry and temperature. These tests have shown that the influence of conditioning is almost negligible for fatigue life higher than $10^{4}$ cycles. This result contributes to fear a loss of conditioning for RH0 and RH100 samples during fatigue tests. So, these tests were repeated in a climatic chamber. Fatigue lives were found equal to those obtain at ambient hygrometry, confirming that the moisture content has less influence in the case of long fatigue lives and therefore of low fatigue stress. Damage analysis was performed using infrared thermography, acoustic emission, microscopic observations and synchrotron XR tomography. All the data monitored have allowed highlighting a change in the damage process depending on the applied fatigue stress. When the loading level is lower than $50 \%$ of the stress at break, the importance of fibre breakage increases. Given that fibres mechanical properties are not affected by the presence of water, this could explain the equivalence of fatigue lives regardless of the conditioning for low fatigue stress levels.

\section{References}

[1] Arif MF, Meraghni F, Chemisky Y, Despringre N, Robert G. In situ damage mechanisms investigation of PA66/GF30 composite: Effect of relative humidity. Compos Part B Eng 2014;58:487-95. http://dx.doi.org/10.1016/ j.compositesb.2013.11.001.

[2] Broudin M, Le Saux V, Le Gac PY, Champy C, Robert G, Charrier P, et al. Moisture sorption in polyamide 6.6: Experimental investigation and comparison to four physical-based models. Polym Test 2015;43:10-20. http:// dx.doi.org/10.1016/j.polymertesting.2015.02.004.

[3] Launay A, Marco Y, Maitournam MH, Raoult I. Modelling the influence of temperature and relative humidity on the time-dependent mechanical behaviour of a short glass fibre reinforced polyamide. Mech Mater 2013;56: 1-10. http://dx.doi.org/10.1016/j.mechmat.2012.08.008.

[4] Benaarbia A, Chrysochoos A, Robert G. Influence of relative humidity and loading frequency on the PA6.6 thermomechanical cyclic behavior: part I. mechanical and thermal aspects. Polym Test 2014;40:290-8.

[5] Jia N, Kagan VA. Mechanical performance of polyamides with influence of moisture and temperature - accurate evaluation and better understanding. Plast Fail Anal Prev 2001:95-104.

[6] Klimkeit B. Etude expérimentale et modélisation du comportement en fatigue multiaxiale d'un polymère renforcé pour application automobile. PhD Thesis. ENSMA; 2009.

[7] Esmaeillou B, Fitoussi J, Lucas a, Tcharkhtchi a. Multi-scale experimental analysis of the tension-tension fatigue behavior of a short glass fiber reinforced polyamide composite. Procedia Eng 2011;10:2117-22. http:// dx.doi.org/10.1016/j.proeng.2011.04.350.

[8] Mallick P, Zhou Y. Effect of mean stress on the stress-controlled fatigue of a short E-glass fiber reinforced polyamide-6,6. Int J Fatigue 2004;26:941-6. http://dx.doi.org/10.1016/j.ijfatigue.2004.02.003.

[9] Ferreira JAM, Costa JDM, Reis PNB, Richardson MOW. Analysis of fatigue and damage in glass-fibre-reinforced polypropylene composite materials. Compos Sci Technol 1999;59:1461-7.

[10] Daggumati S, De Baere I, Van Paepegem W, Degrieck J, Xu J, Lomov SV, et al. Fatigue and post-fatigue stress-strain analysis of a 5-harness satin weave carbon fibre reinforced composite. Compos Sci Technol 2013;74:20-7. http:// 
dx.doi.org/10.1016/j.compscitech.2012.09.012.

[11] Fujii T, Amijima S, Okubo K. Microscopic fatigue processes in a plain-weave glass-fibre composite. Compos Sci Technol 1993;49:327-33. http:// dx.doi.org/10.1016/0266-3538(93)90063-M.

[12] Pandita SD, Huysmans G, Wevers M, Verpoest I. Tensile fatigue behaviour of glass plain-weave fabric composites in on- and off-axis directions. Compos Part A Appl Sci Manuf 2001;32:1533-9. http://dx.doi.org/10.1016/S1359835X(01)00053-7.

[13] Castellano A, Fraddosio A, Piccioni MD. Ultrasonic goniometric immersion tests for the characterization of fatigue post-LVI damage induced anisotropy superimposed to the constitutive anisotropy of polymer composites. Compos Part B 2017;116:122-36.

[14] Munoz V, Valès B, Perrin M, Pastor ML, Welemane H, Cantarel A, et al. Damage detection in CFRP by coupling acoustic emission and infrared thermography. Compos Part B 2016;85:68-75.

[15] Toubal L, Karama M, Lorrain B. Damage evolution and infrared thermography in woven composite laminates under fatigue loading. Int J Fatigue 2006;28: 1867-72. http://dx.doi.org/10.1016/j.ijfatigue.2006.01.013.

[16] Fruehmann RK, Dulieu-Barton JM, Quinn S. Assessment of fatigue damage evolution in woven composite materials using infra-red techniques. Compos Sci Technol 2010;70:937-46. http://dx.doi.org/10.1016/ j.compscitech.2010.02.009.

[17] Liakat M, Khonsari MM. Analysis and life prediction of a composite laminate under cyclic loading. Compos Part B 2016;84:98-108.

[18] Barré S, Benzeggagh ML. On the use of acoustic emission to investigate damage mechanisms in glass-fibre-reinforced polypropylene. Compos Sci Technol 1994:3538:369-76.

[19] Scida D, Aboura Z, Benzeggagh ML. The effect of ageing on the damage events in woven-fibre composite materials under different loading conditions. Compos Sci Technol 2002:62:551-7.

[20] Silva De Vasconcellos D, Touchard F, Chocinski-Arnault L. Tension-tension fatigue behaviour of woven hemp fibre reinforced epoxy composite: A multiinstrumented damage analysis. Int J Fatigue 2014;59:159-69. http:// dx.doi.org/10.1016/j.ijfatigue.2013.08.029.

[21] Taghizadeh J, Najafabadi MA. Classification of acoustic emission signals collected during tensile tests on unidirectional ultra high molecular weight polypropylene fiber reinforced epoxy composites using principal component analysis. Russ J Nondestruct Test 2011;47:491-500. http://dx.doi.org/ $10.1134 /$ S1061830911070084.

[22] Godin N, Huguet S, Gaertner R, Salmon L. Clustering of acoustic emission signals collected during tensile tests on unidirectional glass/polyester composite using supervised and unsupervised classifiers. NDT E Int 2004;37: 253-64. http://dx.doi.org/10.1016/j.ndteint.2003.09.010.

[23] Gutkin R, Green CJ, Vangrattanachai S, Pinho ST, Robinson P, Curtis PT. On acoustic emission for failure investigation in CFRP: Pattern recognition and peak frequency analyses. Mech Syst Signal Process 2011;25:1393-407. http:// dx.doi.org/10.1016/j.ymssp.2010.11.014.

[24] Kempf M, Skrabala O, Altstädt V. Acoustic emission analysis for characterisation of damage mechanisms in fibre reinforced thermosetting polyurethane and epoxy. Compos Part B Eng 2014;56:477-83. http://dx.doi.org/10.1016 j.compositesb.2013.08.080.

[25] Kostopoulos V, Loutas T, Kontsos A, Sotiriadis G, Pappas Y. On the identification of the failure mechanisms in oxide/oxide composites using acoustic emission. NDT E Int 2003;36:571-80. http://dx.doi.org/10.1016/S09638695(03)00068-9.

[26] Moevus M, Godin N, R'Mili M, Rouby D, Reynaud P, Fantozzi G, et al. Analysis of damage mechanisms and associated acoustic emission in two SiCf/[Si-B-C] composites exhibiting different tensile behaviours. Part II: Unsupervised acoustic emission data clustering. Compos Sci Technol 2008;68:1258-65. http://dx.doi.org/10.1016/j.compscitech.2007.12.002.

[27] Ramirez-Jimenez C, Papadakis N, Reynolds N, Gan T, Purnell P, Pharaoh M. Identification of failure modes in glass/polypropylene composites by means of the primary frequency content of the acoustic emission event. Compos Sci
Technol j.compscitech.2004.01.008.

$2004 ; 64: 1819-27$

http://dx.doi.org/10.1016

[28] Madra A, Hajj N El, Benzeggagh M. X-ray microtomography applications for quantitative and qualitative analysis of porosity in woven glass fiber reinforced thermoplastic. Compos Sci Technol 2014;95:50-8. http://dx.doi.org/ 10.1016/j.compscitech.2014.02.009.

[29] Seltzer R, González C, Muñoz R, Llorca J, Blanco-Varela T. X-ray microtomography analysis of the damage micromechanisms in 3D woven composites under low-velocity impact. Compos Part A Appl Sci Manuf 2013;45: 49-60. http://dx.doi.org/10.1016/j.compositesa.2012.09.017.

[30] Jespersen KM, Zangenberg J, Lowe T, Withers PJ, Mikkelsen LP. Fatigue damage assessment of uni-directional non-crimp fabric reinforced polyeste composite using X-ray computed tomography. Compos Sci Technol 2016;136: 94-103.

[31] Hu Y, Lang AW, Li X, Nutt SR. Hygrothermal aging effects on fatigue of glass fiber/polydicyclopentadiene composites. Polym Degrad Stab 2014;110 464-72. http://dx.doi.org/10.1016/j.polymdegradstab.2014.10.018.

[32] Jones CJ, Dickson RF, Adam T, Reiter H, Harris B. The environmental fatigue behaviour of reinforced plastics. Proc R Soc Lond Ser A 1984;396:315-38.

[33] Mcbagonluri F, Garcia K, Hayes M, Verghese KNE, Lesko JJ. Characterization of fatigue and combined environment on durability performance of glass/viny ester composite for infrastructure applications. Int J Fatigue 2000;22:53-64.

[34] Meziere Y, Bunsell AR, Favry Y, Teissedre J, Do AT. Large strain cyclic fatigue testing of unidirectional carbon fibre reinforced epoxy resin. Compos Part A Appl Sci Manuf 2005;36:1627-36. http://dx.doi.org/10.1016/ j.compositesa.2005.03.020.

[35] Patel SR, Case SW. Durability of a graphite/epoxy woven composite under combined hygrothermal conditions. Int J Fatigue 2000;22:809-20.

[36] Siriruk A, Penumadu D. Degradation in fatigue behavior of carbon fiber - vinyl ester based composites due to sea environment. Compos Part B 2014;61: 94-8. http://dx.doi.org/10.1016/j.compositesb.2014.01.030.

[37] Vauthier E. Interactions between hygrothermal ageing and fatigue damage in unidirectional glass/epoxy composites. Compos Sci Technol 1998:58:687-92.

[38] Zhang A, Li D, Lu H, Zhang D. Qualitative separation of the effect of voids on the bending fatigue performance of hygrothermal conditioned carbon/epoxy composites. Mater Des 2011;32:4803-9. http://dx.doi.org/10.1016/ j.matdes.2011.06.028.

[39] Daggumati S, De Baere I, Van Paepegem W, Degrieck J, Xu J, Lomov SV, et al. Local damage in a 5-harness satin weave composite under static tension: Part I - Experimental analysis. Compos Sci Technol 2010;70:1926-33. http:/ dx.doi.org/10.1016/j.compscitech.2010.07.003.

[40] Osada T, Mizoguchi M, Kotaki M. Initial micro fracture behavior of woven fabric composites. ICCM13, Beijing (China). 2001. p. ID1083.

[41] Silva de Vasconcellos D. Comportement en fatigue avant et après impact de composites tissés chanvre/epoxy. Thèse l'ENSMA 2013.

[42] El Mahi A, Ben Salem I, Assarar A, Berbaoui R, Poîlane C, El Guerjouma R. Analyse par émission acoustique de l'endommagement des matériaux écocomposites. Lyon: 10ème Congrès Français d'Acoustique; 2010.

[43] Kotsikos G, Evans JT, Gibson AG, Hale J. Use of acoustic emission to characterize corrosion fatigue damage accumulation in glass fiber reinforced polyester laminates. Polym Compos 1999;20:689-96.

[44] Malpot A, Touchard F, Bergamo S. Effect of relative humidity on mechanical properties of a woven thermoplastic composite for automotive application. $\begin{array}{llll}\text { Polym Test 2015;48:160-8. http://dx.doi.org/10.1016 } & \text { 20 }\end{array}$ j.polymertesting.2015.10.010.

[45] Malpot A, Touchard F, Bergamo S. Influence of moisture on the fatigue behaviour of a woven thermoplastic composite used for automotive application. Mater Des 2016:98:12-9.

[46] Malpot A, Touchard F, Bergamo S. Fatigue behaviour of a thermoplastic composite reinforced with woven glass fibres for automotive application. Procedia Eng 2015;133:136-47.

[47] Carvelli V, Lomov SV. Fatigue of Textile Composites. Woodhead P 2015. 